\title{
RESPONS PETANI TERHADAP PROGRAM ASURANSI USAHA TANI PADI (AUTP) DI KECAMATAN SAJOANGING, KABUPATEN WAJO, PROVINSI SULAWESI SELATAN
}

\author{
Farmer Responses Toward Rice Farming Insurance Program (AUTP) In Sajoanging \\ District, Wajo Regency, South Sulawesi
}

\author{
Dhesrianti Safitri*, Mujahidin Fahmid, Pipi Diansari \\ Program Studi Agribisnis, Departemen Sosial Ekonomi Pertanian, \\ Fakultas Pertanian, Universitas Hasanuddin, Makassar \\ *Kontak penulis: disafitri02@gmail.com
}

\begin{abstract}
ABSTRAK
Asuransi Usaha Tani Padi (AUTP) dapat memberikan jaminan terhadap kerusakan tanaman akibat banjir, kekeringan, serta serangan organisme pengganggu tanaman (OPT), sehingga petani akan memperoleh ganti rugi sebagai modal kerja untuk keberlangsungan usahataninya. Penelitian ini bertujuan untuk: 1) Mendeskripsikan bentuk pelaksanaan program Asuransi Usaha Tani Padi (AUTP) di Kecamatan Sajoanging, Kabupaten Wajo, 2) Menganalisis respon petani terhadap program Asuransi Usaha Tani Padi (AUTP) di Kecamatan Sajoanging, Kabupaten Wajo. Pemilihan lokasi dilakukan secara Purposive Sampling. Penentuan sampel menggunakan proportional sampling dengan mengambil sampel sebanyak $25 \%$ dari populasi berjumlah 214 orang, sehingga sampel dalam penelitian ini berjumlah 53 responden. Analisis data yang digunakan yaitu analisis deskriptif, dan untuk mengukur respon petani dalam hal ini persepsi, sikap, dan motif petani terhadap AUTP digunakan Skala Likert dengan 3 kategori yaitu: tidak setuju (TS), setuju (S), sangat setuju (SS). Hasil penelitian menunjukkan: 1) Pelaksanaan program AUTP di Kecamatan Sajonging tidak berjalan dengan lancar. Mekanisme pelaksanaan AUTP belum sepenuhnya berjalan sesuai dengan dokumen pedoman pelaksanaan AUTP yang ditetapkan oleh pemerintah, 2) Petani di Kecamatan Sajoanging memiliki respon yang baik terhadap program AUTP yang dilihat dari persepsi, sikap, dan motif petani terhadap program AUTP berada pada kategori baik yang menandakan bahwa program AUTP telah diterima dengan baik oleh petani di Kecamatan Sajoanging.
\end{abstract}

Kata Kunci: Respon petani; persepsi; sikap; motif, asuransi usaha tani padi.

\begin{abstract}
Rice Farming Insurance Program (AUTP) can give assurance toward plant damages caused by flood, dryed, and organism attack as plant destroyer, so that farmer can get the replacement as work capital for the sustainability of this farmer works. This research aimed to: 1) Describe the form implementation of Rice Farming Insurance Program (AUTP) In Sajoanging District, Wajo Regency, 2) Analyze the farmer responses toward Rice Farming Insurance Program (AUTP) in Sajoanging District, Wajo Regency. Sample taken by using proportional sampling that it took $25 \%$ from population which has 214 persons, the sample in this study amounted was 53 respondent. Data analysis using was descriptive analysis and to determine the farmer responses in this case is perception, attitude, and motive toward AUTP is used Likert Scale with 3 categories: disagree(TS), agree (S), strongly agree (SS). The result of research shown that: 1) The Rice Farming Insurance Program (AUTP) In Sajoanging District was not run well. Mechanism of implementation AUTP has not fully run in accordance with the AUTP implementation
\end{abstract}


guidance document, 2) Farmer in Sajoanging District has a good response toward the AUTP program it can be seen form perception, attitude, and motive of farmer towards the program that in a good category so that it shown the AUTP program was accepted by the farmer in Sajoanging District.

Keyword: Farmer responses, perception, attitude, motive, Rice Farming Insurance Program (AUTP)

\section{Pendahuluan}

Upaya Kementerian Pertanian untuk mensukseskan pencapaian target swasembada pangan sudah menjadi tekad dan harus berhasil. Berkenaan dengan itu, mulai tahun 2015 pemerintah melaksanakan Upaya Khusus (UPSUS) swasembada padi dengan target produksi padi tahun 2016 mencapai 75,13 juta ton. Usaha di sektor pertanian, khususnya usaha tani padi, dihadapkan pada risiko ketidakpastian sebagai akibat dampak negatif perubahan iklim yang merugikan petani. Untuk mengatasi kerugian petani, maka pemerintah membantu mengupayakan perlindungan usaha tani dalam bentuk Asuransi Pertanian.

Secara konseptual, program uji coba asuransi usaha tani padi merupakan salah satu bentuk program yang diselenggarakan oleh pemerintah dalam rangka untuk melihat sejauh mana program ini dapat secara efektif melindungi petani dari ancaman gagal panen dan memperkenalkan kepada petani bagaimana mekanisme sistem asuransi pertanian berjalan sebagai langkah awal untuk mengembangkan sistem asuransi pertanian di Indonesia dalam skala nasional. Program Asuransi Usaha Tani Padi (AUTP) juga dilaksanakan untuk memberikan wawasan baru kepada petani terkait adanya sistem perlindungan usaha tani dan agar dalam penyelenggarannya dapat berjalan secara efektif perlu melibatkan petani dalam setiap proses kegiatannya.

Kabupaten Wajo merupakan salah satu sentra produksi padi di Sulawesi Selatan. Daerah ini merupakan daerah yang rawan terjadi gagal panen yang diakibatkan oleh banjir dan kekeringan, sehingga pemerintah menyediakan Asuransi Usaha Tani Padi (AUTP) untuk membantu petani dari resiko kegagalan panen. Salah satu kecamatan yang menerapkan asuransi usaha tani padi adalah Kecamatan Sajoanging. Total jumlah petani peserta asuransi di kecamatan tersebut sebanyak 214 orang yang diikuti oleh lima desa dengan luas lahan yang diasuransikan yaitu 300 hektar. Hal ini menandakan bahwa antusias petani untuk mengikuti program AUTP di Kecamatan Sajoanging sangat tinggi. Mengingat program AUTP merupakan program baru, dan masih dalam tahap permulaan, maka penting untuk mengkaji pelaksanaan program Asuransi Usaha Tani Padi (AUTP) serta respon petani mengenai program tersebut. Respon petani terhadap AUTP menjadi penting untuk melihat sejauh mana keberhasilan program ini dapat membantu petani dari resiko kegagalan panen dan agar keberlanjutan program asuransi ini dapat berjalan dengan baik kedepannya.

Oleh karena itu, berdasarkan latar belakang dan permasalahan tersebut maka penelitian ini bertujuan untuk: 1) Mendeskripsikan bentuk pelaksanaan program Asuransi Usaha Tani Padi (AUTP) di Kecamatan Sajoanging, Kabupaten Wajo, 2) Menganalisis respon petani terhadap program Asuransi Usaha Tani Padi (AUTP) di Kecamatan Sajoanging, Kabupaten Wajo. 


\section{Metode Penelitian}

Penelitian ini dilaksanakan di Kecamatan Sajoanging, Kabupaten Wajo, Propinsi Sulawesi Selatan yang pemilihan lokasinya dilakukan secara Purposive Sampling. Pemilihan lokasi tersebut didasarkan pada pertimbangan bahwa kecamatan tersebut merupakan salah satu kecamatan yang menerapkan asuransi usaha tani padi dan merupakan kecamatan dengan peserta terbanyak. Penentuan sampel dalam penelitian ini menggunakan proportional sampling dengan mengambil sampel sebesar $25 \%$ dari populasi sebanyak 214 orang sehingga diperoleh sampel yaitu 53 responden.

Analisis data yang digunakan untuk mencapai tujuan penelitian pertama mengenai bentuk pelaksanaan Program Asuransi Usaha Tani Padi (AUTP) adalah dengan analisis deskriptif.

Untuk mengukur respon petani dalam hal ini persepsi, sikap, dan motif petani terhadap Program Asuransi Usaha Tani Padi (AUTP) digunakan skala Likert. Skala Likert yang digunakan terdiri dari 3 kategori yaitu: tidak setuju (TS), setuju (S), sangat setuju (SS). Adapun rumus yang digunakan untuk menghitung nilai rata-rata terbobot adalah sebagai berikut:

$$
\bar{x}=\frac{\sum f i . w i}{w i}
$$

Dimana:

$\mathrm{x}^{-} \quad=$ rata-rata terbobot

fi $\quad=$ frekuensi

wi $=$ bobot

Setelah rata-rata terbobot diperoleh hasilnya, rentang skala penelitian akan ditentukan untuk menentukan posisi tanggapan sampel. Rentang skala dihitung dengan menggunakan rumus sebagai berikut:

$$
\mathrm{Rs}=(\mathrm{R}(\mathrm{Bobot})) / \mathrm{M}
$$

Dimana:

Rs = Rentang Skala

$\mathrm{R}$ = Bobot erbesar - bobot terkecil

$\mathrm{M}$ = Banyaknya kategori pembobotan

Posisi persepsi, sikap, dan motif dapat dilihat pada tabel berikut ini.

Tabel 1

Rentang skala persepsi, sikap, dan motif petani

\begin{tabular}{lc}
\hline \multicolumn{1}{c}{ Kategori } & Rentang Skala \\
\hline Tidak Setuju (TS) atau Tidak Baik & Rata-rata terbobot 1,00 - 1,66 \\
Setuju (S) atau Baik & Rata-rata terbobot 1,67 - 2,33 \\
Sangat Setuju (SS) atau Sangat Baik & Rata-rata terbobot 2,34 - 3 \\
\hline
\end{tabular}




\section{Hasil Dan Pembahasan}

\section{Pelaksanaan Program Asuransi Usaha Tani Padi (AUTP) di Kecamatan Sajoanging}

Program AUTP di Kecamatan Sajoanging pertama kali dilaksanakan pada tahun 2016 yang diikuti oleh lima desa dari sembilan desa yang ada di Kecamatan Sajoanging. Luas lahan yang diasuransikan yaitu sekitar 300 hektar dari jumlah luas lahan sawah keseluruhan yang ada Kecamatan Sajoanging yaitu 8.430 hektar. Berdasarkan hasil penelitian, ada 2 kelompok tani yang berhasil memperoleh ganti rugi karena kerusakan yang terjadi pada sawahnya akibat kekeringan.

Sosialisasi Program AUTP di Kecamatan Sajoanging dilakukan oleh Dinas Pertanian Kabupaten Wajo, pihak asuransi yaitu Jasindo, PPL, dan POPT-PHP dengan mengundang ketua kelompok tani ke kantor Kecamatan Sajoanging. Karena terbatasnya waktu dan tempat, sosialisasi pada tingkat petani tidak diberikan secara merata atau hanya kepada perwakilan petani saja khususnya hanya pada ketua kelompok tani. Pendaftaran peserta AUTP dilakukan oleh ketua kelompok tani dengan mengisi formulir pendaftaran yang didampingi oleh petugas pertanian. Sebelumnya, petani yang tergabung dalam kelompok tani mengumpulkan datanya berupa identitas diri, berapa lahan yang ingin diasuransikan beserta premi yang dibayar sesuai dengan luas lahan yang diasuransikan kepada ketua kelompok taninya dan juga menyerahkan fotokopi KTP. Premi yang dibayar oleh petani sebesar Rp.36.000,- Hektar/Musim Tanam.

Ketua kelompok tani menyetorkan uang yang dibayarkan petani langsung melalui rekening kelompok ke rekening PT. Jasindo. Kemudian persyaratan yang terkumpul dan bukti pembayaran diserahkan kepada Dinas Pertanian Kabupaten Wajo. Dinas Pertanian yang menyerahkan berkas pendaftaran peserta serta bukti pembayaran ke pihak asuransi (PT Jasindo). Setelah pendaftaran selesai dan diproses, perusahaan asuransi memberikan bukti pembayaran atau kwitansi dan polis asuransi sebagai bukti telah menjadi peserta AUTP. Petani di Kecamatan Sajoanging menerima polis dalam waktu satu bulan. Polis yang telah terbit dapat diambil oleh petani di kantor Dinas Pertanian Kabupaten Wajo.

Ganti rugi diberikan kepada peserta AUTP apabila terjadi banjir, kekeringan atau serangan OPT yang mengakibatkan kerusakan tanaman padi yang dipertanggungkan dengan kondisi persyaratan yaitu intensitas kerusakan mencapai $\geq 75 \%$ dan luas kerusakan mencapai $\geq 75 \%$ pada setiap luas petak alami. Perhitungan kerusakan dilakukan dengan mengukur luas petak sawah masing-masing dan juga luas kerusakan yang dialami, bisa juga dilihat secara kasat mata, jika sudah dinilai rusak $75 \%$, maka klaim bisa diproses, yang menentukan layak atau tidaknya adalah pihak asuransi yaitu PT. Jasindo.

Proses pengajuan klaim pada program AUTP dilakukan oleh petani yang mengalami kerusakan, petani melaporkan kondisi yang dialaminya tersebut ke PPL/POPT-PHP yang ada di Kecamatan Sajoanging dengan melampirkan bukti kerusakan berupa foto dan keterangan luas lahan yang mengalami kerusakan. PPL bersama POPT-PHP akan mensurvei lokasi untuk melihat kerusakan yang dialami. pihak POPT-PHP dan tim dari asuransi pelaksana yang bertugas menilai kerugian akan melakukan pemeriksaan dan perhitungan kerusakan. Petani akan mengisi berita acara hasil pemeriksaan kerusakan (form AUTP-8) berdasarkan yang ada 
dalam pedoman pelaksanaan AUTP dengan melampirkan bukti foto kerusakan. Berdasarkan informasi yang diperoleh, lama waktu yang dibutuhkan oleh pihak asuransi untuk mencairkan uang ganti rugi di Kecamatan Sajoanging adalah kurang lebih satu bulan. Uang ganti rugi (klaim) atas kerusakan lahan yang dialami oleh petani akan ditransfer langsung oleh pihak asuransi pelaksana ke rekening kelompok tani yang mengalami kerusakan lahan.

Dalam pelaksanaan Program AUTP tahun 2016 menurut penuturan Bapak Yusuf selaku Koordinator POPT-PHP untuk Kecamatan Sajoanging ada beberapa desa yang terkena bencana kekeringan dan hama yang mengakibatkan kerusakan tanaman padi petani, namun tidak semua petani yang lahannya terkena kerusakan berhasil dalam persetujuan klaimnya karena dinilai tidak memenuhi syarat untuk diklaim.

\section{Tingkat Respon Petani Terhadap Program Asuransi Usaha Tani Padi (AUTP)}

\section{A. Persepsi Petani Terhadap Program AUTP}

Menurut Walgito (2004), persepsi merupakan suatu proses pengorganisasian, penginterpretasian terhadap stimulus yang diterima oleh organisme atau individu sehingga menjadi sesuatu yang berarti, dan merupakan aktivitas yang integrated dalam diri individu. Respon sebagai akibat dari persepsi dapat diambil oleh individu dengan berbagai macam bentuk. Stimulus mana yang akan mendapatkan respon dari individu tergantung pada perhatian individu yang bersangkutan. Berdasarkan hal tersebut, perasaan, kemampuan berfikir, pengalaman-pengalaman yang dimiliki individu tidak sama, maka dalam mempersepsi sesuatu stimulus, hasil persepsi mungkin akan berbeda antar individu satu dengan individu yang lain.

Secara keseluruhan persepsi petani terhadap program Asuransi Usaha Tani Padi (AUTP) dapat dilihat dari tabel berikut:

Tabel 2

Persepsi Petani Terhadap Program AUTP

\begin{tabular}{|c|c|c|c|}
\hline No & Indikator & $\begin{array}{l}\text { Rata-Rata } \\
\text { Skor }\end{array}$ & Kategori \\
\hline 1 & Persepsi mengenai tujuan program AUTP & 2.28 & Setuju \\
\hline 2 & Persepsi terhadap sosialisasi program & 1.60 & Tidak Setuju \\
\hline 3 & $\begin{array}{l}\text { Persepsi mengenai pendaftaran peserta } \\
\text { program AUTP }\end{array}$ & 2.20 & Setuju \\
\hline 4 & Persepsi tentang premi asuransi & 2.33 & Setuju \\
\hline 5 & $\begin{array}{l}\text { Persepsi tentang subsisdi premi oleh } \\
\text { pemerintah }\end{array}$ & 2.49 & Sangat Setuju \\
\hline 6 & $\begin{array}{l}\text { Persepsi harga pertanggungan yang } \\
\text { ditetapkan }\end{array}$ & 1.69 & Setuju \\
\hline 7 & Persepsi tentang penilaian ganti rugi & 1.35 & Tidak Setuju \\
\hline 8 & Persepsi tentang klaim asuransi & 1.22 & Tidak Setuju \\
\hline \multirow[t]{3}{*}{9} & $\begin{array}{l}\text { Persepsi mengenai manfaat program } \\
\text { AUTP }\end{array}$ & 2.05 & Setuju \\
\hline & Total & 17.21 & \\
\hline & rata-rata & 1.91 & Setuju \\
\hline
\end{tabular}


Berdasarkan Tabel 2 diketahui bahwa secara umum persepsi petani terhadap program AUTP di Kecamatan Sajoanging tergolong pada kategori setuju dengan rata-rata terbobot persepsi secara keseluruhan sebesar 1,91. Pelaksanaan Program AUTP di Kecamatan Sajoanging dapat dikatakan diterima dengan baik oleh petani, mereka memandang bahwa dengan adanya program ini kekhawatiran mereka akan kegagalan usahatani akibat gagal panen dapat terjamin. Terdapat lima indikator persepsi yang masuk pada kategori setuju yang menandakan bahwa pandangan petani terhadap indikator tersebut sudah baik. Indikator tersebut antara lain, tujuan program, pendaftaran peserta, premi asuransi, subsidi premi oleh pemerintah, harga pertanggungan yang ditetapkan dan manfaat program AUTP, sedangkan indikator subsidi premi dari pemerintah berada pada katogori sangat setuju yang menandakan bahwa petani memiliki pandangan yang sangat baik dengan adanya subsidi premi dari pemerintah ini. Terdapat tiga indikator yang masuk ke dalam kategori tidak setuju yaitu indikator sosialisasi program, penilaian ganti rugi, dan klaim asuransi. Indikator yang masuk ke dalam kategori tidak setuju tersebut menandakan bahwa pelaksanaan AUTP dilihat dari sosialisasi, penilaian ganti rugi, dan klaim asuransi belum terlaksana dengan baik.

\section{B. Sikap Petani Terhadap Program AUTP}

Menurut Sarwono (2009:201) sikap (attitude) adalah istilah yang mencerminkan rasa senang, tidak senang, atau perasaan biasa-biasa saja (netral) dari seseorang terhadap sesuatu. Sesuatu itu bisa benda, kejadian, situasi, orang-orang atau kelompok, kalau yang timbul terhadap sesuatu itu adalah perasaan senang, maka disebut sikap positif. Sedangkan perasaan tidak senang disebut sikap negatif. Kalau tidak timbul perasaan apa-apa berarti sikapnya netral.

Secara keseluruhan sikap petani terhadap program AUTP di Kecamatan Sajoanging dapat dilihat sebagai berikut:

Tabel 3

Rekapitulasi Masing-masing Indikator Sikap Petani Terhadap Program AUTP

\begin{tabular}{|c|c|c|c|}
\hline No & Indikator & $\begin{array}{c}\text { Rata-Rata } \\
\text { Skor } \\
\end{array}$ & Kategori \\
\hline 1 & Sikap terhadap tujuan program AUTP & 1,88 & Setuju \\
\hline 2 & Sikap terhadap sosialisasi program & 1.49 & Tidak Setuju \\
\hline 3 & Sikap terhadap premi asuransi & 2.32 & Setuju \\
\hline 4 & Sikap terhadap subsisdi premi oleh pemerintah & 2.81 & Sangat Setuju \\
\hline 5 & Sikap tentang Pelaksanaan program AUTP & 1,86 & Setuju \\
\hline \multirow[t]{3}{*}{6} & Sikap mengenai manfaat program AUTP & 1,37 & Tidak Setuju \\
\hline & Total & 11.73 & \\
\hline & rata-rata & 1,95 & Setuju \\
\hline
\end{tabular}

Berdasarkan tabel 3 dapat dilihat bahwa secara keseluruhan sikap petani terhadap program AUTP berada pada kategori setuju dengan rata-rata terbobot yang diperoleh 1,95 nilai ini berada dalam rentang skala 1,67-2,33. Sikap petani terhadap program AUTP berada dalam kategori setuju yang berarti bahwa petani memiliki perasaan atau penilaian yang baik mengenai program AUTP. Hal tersebut dapat dilihat dari skor sikap yang diperoleh dari masing-masing indikator. Namun, terdapat 2 indikator yang masuk dalam kategori tidak setuju yaitu sikap petani 
terhadap sosialisasi program dan manfaat program AUTP. Pada indikator sosialisasi, petani menilai sosialisasi yang dilakukan tidak benar dan perlu untuk ditingkatkan, karena banyak petani yang hanya memperoleh informasi mengenai AUTP hanya dari ketua kelompok taninya saja sehingga mereka kurang mendapat infomasi yang lengkap mengenai program AUTP seperti penilaian ganti rugi, banyak petani yang kurang memahami bagaimana penilaian agar memperoleh ganti rugi jika gagal panen sehingga dalam hal ini beberapa petani merasa kecewa karena mereka merasa telah mengalami kerusakan namun tidak mendapatkan ganti rugi. Petani menginginkan sosialisasi lebih ditingkatkan dan juga mereka menginginkan agar sosialisasi dapat diberikan setiap akan memasuki musim tanam baru. Pada indikator manfaat program, banyak petani yang tidak merasakan manfaat program AUTP, hal ini dikarenakan mereka mengalami kerusakan dalam usahataninya namun mereka tidak mendapatkan ganti rugi karena kerusakannya tidak mencapai $\geq 75 \%$, sehingga petani berharap penilaian ganti rugi ini perlu ditinjau ulang.

\section{Motif Petani Mengikuti Program AUTP}

Menurut Gufron dan Rini (2012) motif adalah dorongan yang sudah terikat pada suatu tujuan. Motif menunjuk hubungan sistematik antara suatu respon dengan keadaan dorongan tertentu. Motif yang ada pada diri seseorang akan mewujudkan suatu perilaku yang diarahkan pada tujuan mencapai sasaran kepuasan. Motif petani mengikuti program AUTP di Kecamatan Sajoanging dapat dilihat pada tabel berikut:

Tabel 4

Motif Petani Mengikuti Program AUTP

\begin{tabular}{|c|c|c|c|c|c|c|c|}
\hline \multirow{2}{*}{$\begin{array}{l}\mathbf{N} \\
\mathbf{0}\end{array}$} & \multirow[b]{2}{*}{ Motif } & \multicolumn{3}{|c|}{ Skala pengukuran } & \multirow[b]{2}{*}{ Total } & \multirow{2}{*}{$\begin{array}{l}\text { Rata- } \\
\text { rata } \\
\text { skor }\end{array}$} & \multirow[b]{2}{*}{ Kategori } \\
\hline & & $\begin{array}{c}3 \\
(S S)\end{array}$ & $\begin{array}{c}2 \\
(S)\end{array}$ & $\begin{array}{c}1 \\
(\mathrm{TS})\end{array}$ & & & \\
\hline 1 & $\begin{array}{l}\text { Petani sekitar juga menjadi } \\
\text { peserta AUTP }\end{array}$ & - & 37 & 16 & 53 & 1,69 & Setuju \\
\hline 2 & Intervensi dari pemerintah & - & - & 53 & 53 & 1,00 & $\begin{array}{l}\text { Tidak } \\
\text { setuju }\end{array}$ \\
\hline 3 & $\begin{array}{l}\text { Kesadaran sendiri akan } \\
\text { manfaat program AUTP }\end{array}$ & - & 16 & 37 & 53 & 1,30 & $\begin{array}{l}\text { Tidak } \\
\text { setuju }\end{array}$ \\
\hline 4 & $\begin{array}{l}\text { Subsidi premi dari } \\
\text { pemerintah }\end{array}$ & 43 & 10 & - & 53 & 2,81 & $\begin{array}{l}\text { Sangat } \\
\text { setuju }\end{array}$ \\
\hline \multicolumn{5}{|c|}{ Jumlah } & & 6,80 & \multirow{2}{*}{ Setuju } \\
\hline \multicolumn{6}{|c|}{ Rata-rata } & 1,70 & \\
\hline
\end{tabular}

Berdasarkan tabel 4 motif petani mengikuti program AUTP berada pada kategori setuju dengan total skor rata-rata 1,70. Motif petani mengikuti program di Kecamatan Sajoanging tergolong baik yang menunjukkan bahwa petani mengikuti program karena ada dorongan dari lingkungan sekitarnya yaitu rekan petani lainnya juga mengikuti program tersebut sehingga mereka terdorong juga untuk mengikuti program, serta petani melihat hal positif dalam program AUTP dimana premi yang dibayar murah karena adanya subsidi pemerintah sehingga hal ini tentunya mendorong minat petani untuk mengikuti program AUTP tersebut yang dinilainya tidak memberatkan dari segi ekonomi. Tingkat kesadaran petani akan manfaat dari 
program AUTP ini masih sangat rendah, banyak hal yang mempengaruhi penilaian petani akan manfaat program dimana para petani baru diperkenalkan mengenai program ini sehingga mereka masih ragu-ragu mengenai manfaat yang akan mereka terima jika mengikuti program AUTP.

Respon petani mengenai program Asuransi Usaha Tani Padi (AUTP) dilihat dari hasil analisis persepsi, sikap, dan motif petani dapat disimpulkan bahwa petani di Kecamatan Sajoanging yang mengikuti program AUTP memiliki respon yang baik terhadap program tersebut, sehingga dapat diartikan bahwa program AUTP telah berhasil membantu petani dari resiko gagal panen yang dialaminya. Namun, respon beberapa petani yang kurang baik harus diperhatikan oleh pemerintah dan pihak asuransi terkait sebagai bahan evaluasi untuk memperbaiki sistem pelaksaan program AUTP kedepannya agar nantinya program ini tidak kehilangan minat dari petani yang menilai beberapa bagian dari pelaksaan program tidak sesuai dengan harapan mereka.

\section{Kesimpulan}

Berdasarkan hasil dan pembahasan tersebut, maka pada penelitian ini dapat disimpulkan bahwa:

1. Pelaksanaan AUTP di Kecamatan Sajoanging pertama kali dilaksanakan pada tahun 2016 yang diikuti oleh 214 petani. Secara keseluruhan dapat disimpulkan bahwa pelaksanaan program AUTP di Kecamatan Sajonging tidak berjalan dengan lancar. Mekanisme pelaksanaan AUTP belum sepenuhnya berjalan sesuai dengan dokumen pedoman pelaksanaan AUTP yang ditetapkan oleh pemerintah, seperti pada pembayaran ganti rugi atas klaim petani yang mengalami gagal panen.

2. Petani di Kecamatan Sajoanging memiliki respon yang baik terhadap Program Asuransi Usaha Tani Padi (AUTP), yang menandakan bahwa Program AUTP telah diterima dengan baik oleh petani di Kecamatan Sajonging, berdasarkan hasil penelitian, respon petani dapat dilihat dari hasil analisis persepsi, sikap, dan motif petani terhadap Program AUTP. Persepsi petani terhadap Program Asuransi Usaha Tani Padi (AUTP) termasuk dalam kategori baik, artinya petani menerima dengan baik keberadaan program AUTP dan memiliki pandangan yang baik terhadap program AUTP di Kecamatan Sajoanging. Sikap petani terhadap Program Asuransi Usaha Tani Padi (AUTP) di Kecamatan Sajoanging termasuk dalam kategori baik, artinya petani memiliki perasaan atau penilaian yang baik mengenai program AUTP. Motif petani mengikuti Program AUTP tergolong baik yang menunjukkan bahwa petani memiliki nilai positif terhadap program AUTP yang membuat mereka terdorong untuk mengikuti program tersebut diantaranya yaitu adanya subsidi premi dari pemerintah yang tidak memberatkan petani dari segi ekonomi, serta adanya pengaruh dari petani lain yang membuat mereka juga terdorong untuk mengikuti program AUTP.

\section{Daftar Pustaka}

Sarwono, S.W. 2002. Psikologi Sosial : Individu dan Teori-Teori Psikologi Sosial. Balai Pustaka. Jakarta. 
Walgito, B. 2000. Psikologi Sosial (Suatu pengantar). Penerbit Andi. Yogyakarta.

M. Nur Ghufron Dan Rini Risnawita S. 2012. Teori-Teori Psikologi. (Jogjakarta: ArRuzz Media, 2012), Hal 83 